\title{
ANTIHYPERTENSIVE EFFECT OF RUTIN: PHARMACOLOGICAL AND COMPUTATIONAL APPROACH
}

\author{
GANGA RAJU M*, PREM PRASAD GOUD, SUVARCHALA REDDY NVL
}

Department of Pharmacology, Gokaraju Rangaraju College of Pharmacy, Bachupally, Hyderabad, Telangana. Email:mgrpharma@gmail.com

Received: 14 May 2019, Revised and Accepted: 14 June 2019

\begin{abstract}
Objective: Phenolic compounds, such as flavonoids, have aroused great scientific interest due to their diverse pharmacological activities. Several studies suggested that flavonoids act as antihypertensive by inhibiting angiotensin-converting enzyme (ACE). In the present study, rutin, which is a citrus flavonoid, was evaluated for its antihypertensive activity using in vivo and in vitro models. Rutin was screened for in vitro assay procedures such as diphenylpicrylhydrazyl and nitroblue tetrazolium (NBT) for its antioxidant activity.
\end{abstract}

Methods: Its antihypertensive effect was investigated in $\mathrm{N}^{\omega}$-Nitro-l-arginine methyl ester hydrochloride-induced hypertensive rats, and various parameters such as blood pressure and heart rate were measured; in vitro ACE inhibitory activity was carried out against ACE, aiming at a better understanding of the interaction of this flavonoid with the enzyme. To understand its binding affinity with the angiotensin-converting enzyme, molecular docking studies were carried out using ligand fit of Maestro 9.1 (Schrodinger Software Inc.). An in silico study of rutin was performed for the prediction of Absorption, distribution, metabolism and elimination (ADME) by utilizing a web-based program (www.swissadme.ch). This software computes physicochemical descriptors as well as predicts pharmacokinetic properties and drug-like nature of one or multiple small molecules (blood-brain barrier, cytochromes P450, and P-glycoproteins).

Results: Rutin at different dose levels of 200 and $400 \mathrm{mg} / \mathrm{kg}$ was tested, and the results have shown its antihypertensive, hypotensive, and negative chronotropic effects. Its antihypertensive activity might be mediated through angiotensin-converting enzyme inhibition (half maximal inhibitory concentration $=66.01 \mu \mathrm{g} / \mathrm{mL}$ ). In vitro studies also revealed the antioxidant activity of rutin, thus playing a major role in reducing oxidative stress associated with hypertension. The rutin showed optimum binding affinity with a molecular target (angiotensin-converting-enzyme) with the binding energy of $-9.0 \mathrm{kcal} / \mathrm{mol}$ as compared to the standard $(-6.3 \mathrm{kcal} / \mathrm{mol})$. These results indicated that rutin is one of the potential ligands to treat hypertension. ADME results revealed the three violations of rutin (such as molecular mass, hydrogen donor, and acceptors) of five, and the standard captopril has got zero violations which clearly indicated the probability for its higher oral bioavailability.

Conclusion: From the above, it is concluded that rutin possesses antioxidant and antihypertensive activities.

Keywords: $\mathrm{N}^{\omega}$-Nitro-l-arginine methyl ester hydrochloride, Antioxidant, Hypertension, Angiotensin-converting enzyme, Rutin, ADME, Molecular docking. (C) 2019 The Authors. Published by Innovare Academic Sciences Pvt Ltd. This is an open access article under the CC BY license (http://creativecommons. org/licenses/by/4. 0/) DOI: http://dx.doi.org/10.22159/ajpcr.2019.v12i8.34118

\section{INTRODUCTION}

The compounds such as flavonoids are found in plants and are consumed in the form of fruits, nuts, vegetables, and derivative foods such as wine and brunette. The diet consumed by the western countries mostly comprises quercetin [1]. Quercetin is an example of a flavonoid group which is found in nutriments having sugars, chiefly as $\beta$-glycosides. Rutin, also called rutoside, is the glycoside linking the flavonol quercetin and the disaccharide rutinose. This citrus flavonoid is found in a wide diversity of plants. Rutin is a nutritional flavonoid which has established prodigious consideration, due to their pharmacological properties, including antimicrobial, anti-inflammatory, anticancer, antidiabetic, and inter alia [2].

Although flavonoids are lacking typical nutritive value, they are gradually more regarded as valuable dietary constituents that act as probable defenders contrary to human diseases such as coronary heart disease, cancers, and inflammatory bowel disease. Rutin turns out to be a quercetin releaser to the gut; moreover, quercetin is widely broken down in the gut and released from rutin, and/or its colonic metabolites might play a vital role [3].

Hypertension induced by $\mathrm{N}^{\omega}$-Nitro-l-arginine methyl ester hydrochloride (L-NAME), a nitric oxide synthase (NOS) inhibitor, is a frequently used model in higher mammals. L-NAME-treated rats have downregulated eNOS protein expression in blood vessels and exhaustion of plasma
NO levels, which leads to systemic vasoconstriction, increased vascular resistance, and high blood pressure. There is an association between L-NAME-induced hypertension and oxidative stress indicators. L-NAME at a high dose $(40 \mathrm{mg} / \mathrm{kg} /$ day $)$ has been stated to raise the levels of oxidative stress markers such as vascular superoxide $\left(\mathrm{O}_{2}^{-}\right)$, plasma malondialdehyde, and plasma protein carbonyl. It has been accepted that oxidative stress contributes to the etiology of hypertension in animals and humans as categorized by the augmented bioavailability of reactive oxygen species (ROS) in hypertension [4]. Raised levels of ROS stimulate vascular smooth muscle cell propagation and increase arterial resistance due to reducing NO availability, leading to the damage of vascular relaxation [5]. There is an indication that it is the ROS-producing enzyme, $\beta$-Nicotinamide adenine dinucleotide phosphate oxidase (NOx), that is responsible for increased vascular $\mathrm{O}_{2}^{--}$production in L-NAME hypertensive rats via upregulation of the NOx subunit p47 [6].

To understand the ligand-binding properties of rutin with the angiotensin-converting enzyme (ACE), the test compound rutin was subjected to molecular docking studies. These studies act as a computational tool to expect the probable interactions between rutin and protein. An in silico study of rutin was performed by SwissADME to calculate its pharmacokinetics, drug-likeness, and medicinal chemistry friendliness of trivial molecules to support drug discovery [7]. Different rutin preparations could fetch this encouraging flavonoid to become the leader of nutraceuticals for the deterrence and/or management of numerous chronic human diseases. 


\section{MATERIALS AND METHODS}

\section{Animals}

Healthy Sprague Dawley rats, weighing approximately 150-200 g, were selected for the study. They were retained in a workroom with a $12 \mathrm{~h} \mathrm{light/dark} \mathrm{cycle.} \mathrm{During} \mathrm{the} \mathrm{experiment,} \mathrm{the} \mathrm{room} \mathrm{temperature}$ was maintained at $25^{\circ} \mathrm{C}$. The rats were kept on a standard chow diet and water ad libitum proceeding to dietetic management. They were trained for the $1^{\text {st }}$ week to become familiarized with the technique of indirect blood pressure measurement. All the experimental works with the animals were carried out after obtaining approval from the institutional animal ethics committee (Reg. No. 1175/ac/08/CPCSEA).

\section{In vitro antioxidant assays}

Diphenylpicrylhydrazyl (DPPH) radical scavenging activity

The ability of rutin to donate hydrogen was observed in the occurrence of DPPH stable radical. $1 \mathrm{~mL}$ of $0.3 \mathrm{mM}$ DPPH solution was mixed with $2.5 \mathrm{~mL}$ of test compound of various concentrations and permitted to react at room temperature. The absorbance values were measured at $517 \mathrm{~nm}$ after half an hour. Methanol $(1.0 \mathrm{~mL})$ and the test substance rutin $(2.5 \mathrm{~mL})$ were kept as blank, DPPH solution $(1.0 \mathrm{~mL}$ and $0.3 \mathrm{mM})$, and methanol $(2.5 \mathrm{~mL})$ as a negative control. Vitamin $\mathrm{C}$ was used as standard [8].

\section{Nitroblue tetrazolium reduction assay}

A reaction mixture of $3 \mathrm{~mL}$ was prepared with $1.4 \mathrm{~mL}$ of $50 \mathrm{mM} \mathrm{KH}_{2} \mathrm{PO}_{4}^{-}$ $\mathrm{KOH}$ at $\mathrm{pH} 7.4$ containing $1 \mathrm{mM}$ ethylenediaminetetraacetic acid, $0.5 \mathrm{~mL}$ of $100 \mu \mathrm{M}$ hypoxanthine, and $0.5 \mathrm{~mL}$ of $100 \mu \mathrm{M}$ NBT. The reaction was initiated by adding 0.066 units per tube of xanthine oxidase diluted in $100 \mu \mathrm{L}$ of phosphate buffer freshly and $0.5 \mathrm{~mL}$ of rutin in saline solution. The reduction rate of NBT was determined by spectrophotometric method at $560 \mathrm{~nm}$. Gallic acid was used as standard. The outcomes were expressed as the percentage inhibition of NBT [8].

\section{In vitro ACE inhibitory activity}

In vitro ACE inhibitory activity was measured using the hippurylhistidyl-leucine (HHL), as substrate, ACE (EC 3.4.15.1) obtained from rabbit lung. Rutin at different concentrations $(40 \mu \mathrm{L})$ was incubated with $100 \mu \mathrm{L}$ of $0.1 \mathrm{M}$ borate buffer ( $\mathrm{pH} 8.3$ ) containing $5 \mathrm{mM} \mathrm{HHL}$ and $0.3 \mathrm{M} \mathrm{NaCl}$ and with $20 \mu \mathrm{L}$ of ACE $(2 \mathrm{mU})$ at $37^{\circ} \mathrm{C}$ for $30 \mathrm{~min}$. The reaction was terminated with $150 \mu \mathrm{L}$ of $1 \mathrm{M} \mathrm{HCl}$. The hippuric acid formed was extracted with ethyl acetate $(1000 \mu \mathrm{l})$ and centrifuged at $1500 \mathrm{rpm}$ for $10 \mathrm{~min}$, and $750 \mu \mathrm{L}$ of the organic phase was evaporated. The residue was made up to $800 \mu \mathrm{L}$ with distilled water, and the absorbance at $228 \mathrm{~nm}$ was measured. Triplicates were performed for each sample. Inhibitory activity was expressed as the protein concentration (Pierce, Rockford, IL, USA) using bovine serum albumin as standard needed to inhibit $50 \%$ of ACE activity (half maximal inhibitory concentration $\left(\mathrm{IC}_{50}\right)[9]$.

\section{In vivo study of rutin on hypertensive rats}

Thirty healthy Sprague Dawley rats weighing 150-200 g were used for the study. They were divided into 5 groups of 6 animals each. Hypertension is induced in Sprague Dawley rats by administrating the L-NAME hydrochloride $(50 \mathrm{mg} / \mathrm{kg}$, p.o.) consecutively for 21 days. L-NAME hydrochloride at a dose of $50 \mathrm{mg} / \mathrm{kg}$ was given to all groups except the control group. Group I received $0.5 \mathrm{~mL} / \mathrm{kg}$ p.o. of normal saline. Group II received only L-NAME at a dose of $50 \mathrm{mg} / \mathrm{kg}$. Group III and Group IV received rutin a dose of 200 and $400 \mathrm{mg} / \mathrm{kg}$ p.o. Group $V$ received the standard drug captopril at a dose of $60 \mathrm{mg} / \mathrm{kg}$ after 60-90 min of L-NAME hydrochloride administration. Systolic blood pressure (SBP) and heart rate (HR) were measured by the noninvasive blood pressure amplifier system (PowerLab, ADInstruments, Australia) on days $0,7,14$ and 21 [10].

\section{Docking studies}

The crystallographic structure of the enzymatic target ACE was obtained from the Protein Data Bank (PDB) database (PDB: 1086). The molecular docking study was performed using Schrodinger software 5.6. The docking analysis of the compounds with ACE was carried out by ligand fit of Maestro 9.1 (Schrodinger Software Inc.). The software allows us to virtually screen a database of compounds and predict the strongest binders based on various scoring functions. The collection of enzymesubstrate complexes was identified via docking, and their relative stabilities were evaluated using their binding affinities. Ligand fit was used for accurately docking ligands into protein active sites employing a cavity detection algorithm. A high-throughput screening study applied to the ACE receptor is also presented in which ligand fit when combined with LigScore, an internally developed scoring function, yields very good hit rates for a ligand pool seeded with known actives [11].

\section{Docking protocol}

Protein preparation

The crystal structure of ACE 1086 was prepared, and the active site was identified. The ligands and crystallographic water molecules were removed from the protein, and the chemistry of the protein was corrected for missing hydrogen. Crystallographic disorders and unfilled valence atoms were corrected using alternate conformations and valence monitor options. Following the above steps of preparation, the protein was subjected to energy minimization using the CHARMM force field.

\section{Ligand preparation}

The three-dimensional structure of compounds were downloaded in structure data file format from PubChem and ChemDraw database. Hydrogen bonds were added and the energy was minimized using CHARMM force field. The parameters like G score, hydrogen bond, rotatable bond penalty and a liphophilic term derived from the hydrophobic grid for the rutin and captopril are reported in Table 1.

\section{Docking studies}

The active site of the protein was first identified and it is defined as the binding site. The binding sites were defined based on the ligands already present in the PDB file (i.e., ACE-binding site region) which were followed by site sphere definition. The determination of the ligand-binding affinity was calculated using LigScore and dock score to estimate the ligand-binding energies. Apart from these, other input parameters for docking were set as default options.

\section{ADME studies}

An in silico pharmacokinetic study of rutin was performed for the prediction of ADME properties like molecular weights, topological polar surface area (TPSA), miLog P, number of rotatable bonds, number of hydrogen donor and acceptor atoms (Lipinski 2001). In the present study, ADME was done by utilizing a web-based program (www. swissadme.ch). This software computes physicochemical descriptors as well as predicts pharmacokinetic properties and drugs such as nature of one or multiple small molecules (blood-brain barrier [BBB], cytochromes P450, and P-glycoproteins). The compounds with positive values can cross readily in the $\mathrm{BBB}$, while compounds with negative values are poorly distributed to the brain [12].

\section{Statistical analysis}

All the values were expressed as the mean \pm standard error of mean. The data were statistically analyzed by one-way analysis of variance,

Table 1: Summary of interaction profile generated by Schrodinger (Maestro 9.1) scored by energy function, $\mathrm{H}$ bonding energy, Rotatable bond penalty and liphophilic term

\begin{tabular}{lllll}
\hline Title 1086 & G score & XP H Bond & $\begin{array}{l}\text { XP Rot } \\
\text { Penal }\end{array}$ & $\begin{array}{l}\text { XP Lipophilic } \\
\text { EvdW }\end{array}$ \\
\hline Rutin & -9 & -1.49 & 0.06 & -1.71 \\
Captopril & -6.03 & -1.89 & 0.00 & -0.68 \\
\hline
\end{tabular}

G score=glide score, Lipophilic EvdW=Lipophilic term derived from hydrophobic grid potential, $\mathrm{H}$ bond=hydrogen-bonding term, Rot Penal=Rotatable bond penalty, PDB: Protein Data Bank, ACE: Angiotensin-converting enzyme 
followed by Dunnett's test, and $\mathrm{p}<0.05$ was considered to be statistically significant.

\section{RESULTS}

In vitro antioxidant activity of test compound rutin

Rutin was screened for its antioxidant activity using DPPH and NBT assays.

\section{DPPH radical scavenging assay}

Rutin was tested for free radical scavenging activity using the DPPH method. The concentrations and percentage inhibition values were recorded, and from the percentage inhibition, the $\mathrm{IC}_{50}$ value of rutin and Vitamin C are calculated and is reported in Table 2. Vitamin C (standard) was tested at different dose levels and found to be linear, which substantiates the use of ascorbic acid for comparison of the test doses. $\mathrm{IC}_{50}$ of rutin was $16.5 \mu \mathrm{g} / \mathrm{mL}$ and Vitamin C was $3.89 \mu \mathrm{g} / \mathrm{mL}$.

The assay was performed in triplicate. The above results showed that rutin and Vitamin $\mathrm{C}$ have antioxidant activity.

The DPPH radical was widely used as the model system to investigate the scavenging activity on several natural compounds such as phenolics and anthocyanins. DPPH radical is scavenged by antioxidants through the donation of proton forming the reduced DPPH. The color changes from purple to yellow after reduction, which can be quantified by its decrease of absorbance at wavelength $517 \mathrm{~nm}$.

Radical scavenging activity increased with an increased percentage of free radical inhibition. DPPH is a relatively stable free radical. The assay is based on the measurement of the scavenging ability of antioxidants toward the stable radical DPPH. These radicals react with suitable reducing agents, the electrons become paired off, and the solution loses color depending on the number of electrons taken up [13]. The results revealed the definite scavenging activity of the rutin toward DPPH radical in comparison with standard Vitamin C.

\section{NBT inhibition assay}

Rutin was tested for superoxide scavenging activity using NBT method. The concentrations versus percentage inhibition values were recorded, and from the determination of free radical scavenging activity and antitumor activity of some Myanmar herbal plants, $\mathrm{IC}_{50}$ value of rutin and gallic acid was calculated and is reported in Table 3 . The standard gallic acid was tested at different dose levels and found to be linear, which substantiates the usefulness of gallic acid for comparison of the test doses. IC $_{50}$ of rutin was $7.2 \mu \mathrm{g} / \mathrm{mL}$ and gallic acid was $2.5 \mu \mathrm{g} / \mathrm{mL}$.

The assay was performed in triplicate. The above results showed that rutin and gallic acid have antioxidant activity.

Superoxide dismutase (SOD) is an antioxidant enzyme that neutralizes the free radicals in the cell; it dismutates superoxide anion $\left(\mathrm{O}_{2}^{-}\right)$into $\mathrm{H}_{2} \mathrm{O}_{2}$ and protects the cells from damage by cleaning up $\mathrm{O}_{2}^{-}$. The level of SOD activity represents the intracellular antioxidant ability. Superoxide anion radical is one of the strongest ROS among the free radicals that are generated [14]. Superoxide is produced from molecular oxygen by oxidative enzymes as well as via non-enzymatic reaction such as autoxidation by catecholamines. In the present study, superoxide radical reduces NBT to a blue-colored formazan that is measured at $560 \mathrm{~nm}$.

The above results suggested that rutin has antioxidant activity (DPPH: $\mathrm{IC}_{50}=16.5 \mu \mathrm{g} / \mathrm{mL}$ and NBT: $\mathrm{IC}_{50}=7.2 \mu \mathrm{g} / \mathrm{mL}$ ). Hence, rutin was further proceeded for in vivo antihypertensive activity in L-NAME-induced hypertension in Sprague Dawley rats.

Table 2: Effect of rutin on DPPH radical scavenging assay

\begin{tabular}{|c|c|c|c|c|c|}
\hline \multicolumn{3}{|l|}{ Rutin } & \multicolumn{3}{|l|}{ Vitamin C } \\
\hline Concentration $(\mu \mathrm{g} / \mathrm{mL})$ & $\begin{array}{l}\text { Percentage inhibition } \\
\text { (Mean } \pm \text { SEM) }\end{array}$ & $\mathrm{IC}_{50}(\mu \mathrm{g} / \mathrm{mL})$ & Concentration $(\mu \mathrm{g} / \mathrm{mL})$ & $\begin{array}{l}\text { Percentage inhibition } \\
\text { (Mean } \pm \text { SEM) }\end{array}$ & $\mathrm{IC}_{50}(\mu \mathrm{g} / \mathrm{mL})$ \\
\hline 25 & $63.09 \pm 0.42$ & 16.5 & 6.25 & $79.73 \pm 1.03$ & 3.89 \\
\hline 12.5 & $51.80 \pm 0.21$ & & 3.12 & $42.72 \pm 0.26$ & \\
\hline 6.25 & $34.51 \pm 0.96$ & & 1.56 & $21.28 \pm 0.51$ & \\
\hline 3.12 & $20.64 \pm 0.42$ & & 0.78 & $20.12 \pm 0.10$ & \\
\hline
\end{tabular}

DPPH: Diphenylpicrylhydrazyl, IC IC $_{50}$ Half maximal inhibitory concentration, SEM: Standard error of mean

Table 3: Effect of rutin on NBT inhibition assay

\begin{tabular}{|c|c|c|c|c|c|}
\hline \multicolumn{3}{|l|}{ Rutin } & \multicolumn{3}{|l|}{ Gallic acid } \\
\hline Concentration $(\mu \mathrm{g} / \mathrm{mL})$ & $\begin{array}{l}\text { Percentage inhibition } \\
\text { (Mean } \pm \text { SEM) }\end{array}$ & $\mathrm{IC}_{50}(\mu \mathrm{g} / \mathrm{mL})$ & Concentration $(\mu \mathrm{g} / \mathrm{mL})$ & $\begin{array}{l}\text { Percentage inhibition } \\
\text { (Mean } \pm \text { SEM) }\end{array}$ & $\mathrm{IC}_{50}(\mu \mathrm{g} / \mathrm{mL})$ \\
\hline 25 & $82.80 \pm 0.37$ & 7.2 & 25 & $90.35 \pm 0.53$ & 2.5 \\
\hline 12.5 & $64.63 \pm 0.17$ & & 12.5 & $82.29 \pm 0.02$ & \\
\hline 6.25 & $43.10 \pm 0.88$ & & 6.25 & $74.09 \pm 0.29$ & \\
\hline 3.125 & $25.18 \pm 0.10$ & & 3.17 & $63.12 \pm 0.36$ & \\
\hline
\end{tabular}

NBT: Nitroblue tetrazolium, $\mathrm{IC}_{50}$ : Half maximal inhibitory concentration, SEM: Standard error of mean

Table 4: Effect of rutin on ACE inhibition assay

\begin{tabular}{|c|c|c|c|c|c|}
\hline \multicolumn{3}{|l|}{ Rutin } & \multicolumn{3}{|l|}{ Captopril } \\
\hline Concentration $(\mu \mathrm{g} / \mathrm{mL})$ & $\begin{array}{l}\text { Percentage inhibition } \\
(\text { Mean } \pm \text { SEM) }\end{array}$ & $\mathrm{IC}_{50}(\mu \mathrm{g} / \mathrm{mL})$ & Concentration $(\mu \mathrm{g} / \mathrm{mL})$ & $\begin{array}{l}\text { Percentage inhibition } \\
(\text { Mean } \pm \text { SEM) }\end{array}$ & $\mathrm{IC}_{50}(\mu \mathrm{g} / \mathrm{mL})$ \\
\hline 100 & $77.25 \pm 0.22$ & 66.01 & - & - & 20.31 \\
\hline 50 & $35.50 \pm 0.08$ & & 50 & $85.20 \pm 0.62$ & \\
\hline 25 & $19.50 \pm 0.87$ & & 25 & $59.82 \pm 0.88$ & \\
\hline 12.5 & $10.25 \pm 0.19$ & & 12.5 & $30.12 \pm 0.01$ & \\
\hline
\end{tabular}

$\mathrm{IC}_{55}$ : Half maximal inhibitory concentration, ACE: Angiotensin-converting enzyme, SEM: Standard error of mean 
Rutin was also screened for in vitro ACE inhibition assay for antihypertensive activity. Inhibitory activity of ACE plays a major role in the treatment of L-NAME-induced hypertensive animals. Hence, the test compound and standard drug are screened for ACE inhibition assay at different concentrations, and the $\mathrm{IC}_{50}$ value is calculated.

\section{In vitro ACE inhibition assay}

Rutin was tested for ACE inhibitory activity using the ACE inhibition assay method. The concentrations and percentage inhibition of rutin and standard drug captopril were recorded. From the percent inhibition, $\mathrm{IC}_{50}$ values were calculated and are reported in Table 4. The standard drug captopril was tested at different dose levels and found to be linear, which substantiates the usefulness of captopril for comparison of the test doses. $\mathrm{IC}_{50}$ of rutin was $66.01 \mu \mathrm{g} / \mathrm{mL}$ and captopril was $20.31 \mu \mathrm{g} / \mathrm{mL}$

The assay was performed in triplicate. The above results show that the test extract rutin and standard compound captopril have antihypertensive activity

Rutin has antihypertensive activity by ACE inhibitory action $\left(\mathrm{IC}_{50}=66.01 \mu \mathrm{g} / \mathrm{mL}\right)$. In vitro studies have revealed the antioxidant activity of rutin and the role of rutin in reducing oxidative stress associated with hypertension. Hence, the test compound is preceded for in vivo antihypertensive activity in L-NAME-induced hypertension in Sprague Dawley rats using captopril

\section{In vivo studies of rutin on SBP and HR in Sprague Dawley rats} Effect of rutin on $S B P$

The test compound rutin was tested for its effect on SBP of L-NAMEinduced hypertension in Sprague Dawley rats. SBP was recorded on a weekly basis, i.e., on day 0 , day 7 , day 14 , and day 21 . SBP ( $\mathrm{mmHg}$ ) was measured using the NIBP system for all groups of animals. The results are reported in Table 5.

Animals treated with L-NAME at $50 \mathrm{mg} / \mathrm{kg}$ bd. wt showed a significant increase in the SBP as compared to a normal control group, and this might be due to the inhibition of NO synthesis. Oral administration of rutin at a dose of $200 \mathrm{mg} / \mathrm{kg}$ and $400 \mathrm{mg} / \mathrm{kg}$ bd. wt significantly decreased the SBP in treatment groups when compared to the L-NAME control group, and this might be due to the inhibition of ACE activity [15]. The standard drug captopril at a dose of $60 \mathrm{mg} / \mathrm{kg}$ bd. wt has shown a significant reduction in SBP.

\section{Effect of rutin on $H R$}

Rutin was tested for its effect on the HR of L-NAME-induced hypertension in Sprague Dawley rats. HR was recorded on a weekly basis, i.e.,on day 0 , day 7 , day 14 , and day 21 . HR (beats per minute) was measured using the NIBP system for all groups. The results are reported in Table 6

Animals treated with L-NAME at $50 \mathrm{mg} / \mathrm{kg}$ bd. wt showed a significant increase in the HR as compared to the normal control group, and this might be due to compensatory baroreceptor reflex mechanism [16] which shows a relationship between HR and blood pressure variability in rats. Oral administration of rutin at a dose of $200 \mathrm{mg} / \mathrm{kg}$ and $400 \mathrm{mg} / \mathrm{kg}$ bd. wt significantly decreased the HR in treatment groups when compared to the L-NAME control group, and this might be due to ACE inhibitory activity [17]. The standard drug captopril at a dose of $60 \mathrm{mg} / \mathrm{kg}$ bd. wt has shown a significant decrease in HR.

Regulation of body weight is also one of the parameter studied in hypertension like in obese rats [18]. Hypertension is a metabolic syndrome which affects the body weight also, so the test compound

Table 5: Effect of rutin on SBP of L-NAME-induced hypertensive Sprague Dawley rats

\begin{tabular}{|c|c|c|c|c|c|}
\hline \multirow[t]{2}{*}{ Groups } & \multirow[t]{2}{*}{ Treatment } & \multicolumn{4}{|l|}{$\mathrm{SBP}(\mathrm{mm} / \mathrm{Hg})$} \\
\hline & & Day 0 & Day 7 & Day 14 & Day 21 \\
\hline Group I & Normal & $108.85 \pm 0.43$ & $107.27 \pm 0.51$ & $102.47 \pm 0.92$ & $110.41 \pm 0.08$ \\
\hline Group II & L-NAME+Vehicle & $106.67 \pm 0.46^{* *, a}$ & $137.03 \pm 0.43^{* *, a}$ & $150.92 \pm 0.04^{* *, a}$ & $161.33 \pm 0.92^{* *, a}$ \\
\hline Group III & L-NAME+Rutin (200 mg/kg bd. wt) & $108.93 \pm 0.23^{* * \text {,ns }}$ & $145.75 \pm 0.27^{* *, a}$ & $136.13 \pm 0.13^{* *, a *}$ & $131.22 \pm 0.98^{* *, a}$ \\
\hline Group IV & L-NAME+Rutin (400 mg/kg bd. wt) & $108.09 \pm 0.22^{* * \text {,ns }}$ & $137.97 \pm 0.24^{* *, a}$ & $129.47 \pm 0.59^{* *, a}$ & $120.34 \pm 0.53^{* *, a}$ \\
\hline Group V & L-NAME+Captopril (60 mg/kg bd. wt) & $108.48 \pm 0.51^{* *}$ & $103.13 \pm 0.69 * *$ & $110.39 \pm 0.62^{* *}$ & $111.92 \pm 0.44^{* *}$ \\
\hline
\end{tabular}

Values are expressed as mean \pm SEM $(\mathrm{n}=6)$. The test groups are compared to L-NAME control group. Significant values are expressed as $\left({ }^{*} \mathrm{p}<0.05,{ }^{* *} \mathrm{p}<0.01\right)$ compared to control, ( $\left.{ }^{a} \mathrm{p}<0.01,{ }^{b} \mathrm{p}<0.01\right)$ to standard ( ${ }^{\mathrm{s}}$ non significant), L-NAME: ${ }^{\omega}{ }^{\omega}$-Nitro-l-arginine methyl ester hydrochloride, SBP: Systolic blood pressure

Table 6: Effect of test compound rutin on the HR of L-NAME-induced hypertensive Sprague Dawley rats

\begin{tabular}{|c|c|c|c|c|c|}
\hline \multirow[t]{2}{*}{ Groups } & \multirow[t]{2}{*}{ Treatment } & \multicolumn{4}{|l|}{ HR (BPM) } \\
\hline & & Day-0 & Day-7 & Day-14 & Day-21 \\
\hline Group I & Normal control & $305.49 \pm 0.12$ & $308.02 \pm 0.29$ & $314.25 \pm 0.65$ & $312.06 \pm 0.54$ \\
\hline Group II & L-NAME+vehicle (50 mg/kg bd. wt) & $308.8 \pm 0.55^{* *, a}$ & $352.41 \pm 0.54^{* *, a}$ & $374.68 \pm 0.51^{* *, a}$ & $404.57 \pm 0.13^{* *, a}$ \\
\hline Group III & L-NAME+Rutin (200 mg/kg bd. wt) & $302.42 \pm 0.15^{* * \text {,ns }}$ & $356.30 \pm 0.05^{* * \text {,ns }}$ & $348.93 \pm 0.21 * *, a$ & $324.60 \pm 0.96^{*, a}$ \\
\hline Group IV & L-NAME+Rutin (400 mg/kg bd. wt) & $302.80 \pm 0.15^{* * \text {,ns }}$ & $350.10 \pm 0.65^{* *, \mathrm{~b}}$ & $324.10 \pm 0.82 * *, \mathrm{~b}$ & $312.33 \pm 0.25^{* *, a}$ \\
\hline Group V & L-NAME+Captopril $(60 \mathrm{mg} / \mathrm{kg}$ bd. wt) & $303.12 \pm 0.02^{* *}$ & $354.52 \pm 0.98^{* *}$ & $326.71 \pm 0.74^{* *}$ & $314.80 \pm 0.73^{* *, \mathrm{~b}}$ \\
\hline
\end{tabular}

Values are expressed as mean \pm SEM $(n=6)$. The test groups are compared to L-NAME control group. Significant values are expressed as $\left({ }^{*} \mathrm{p}<0.05\right.$, $\left.{ }^{* *} \mathrm{p}<0.01\right)$ compared to control, $\left({ }^{\mathrm{a}} \mathrm{p}<0.01,{ }^{\mathrm{b}} \mathrm{p}<0.01\right)$ to standard $\left({ }^{\mathrm{ns}}\right.$ non significant), L-NAME: $\mathrm{N}^{\omega}$-Nitro-l-arginine methyl ester hydrochloride, HR: Heart rate, BPM: Beats per minute

Table 7: ADME profile of rutin and captopril

\begin{tabular}{|c|c|c|c|c|c|c|c|c|}
\hline \multirow[t]{2}{*}{ Compound name } & \multicolumn{6}{|c|}{ Physiochemical properties } & \multirow{2}{*}{$\begin{array}{l}\text { Lipophilicity } \\
\text { ilOGP }\end{array}$} & \multirow{2}{*}{$\begin{array}{l}\text { Water Solubility } \\
\text { Log S/Solubility }\end{array}$} \\
\hline & Mol wt g/mol & TPSA $\AA^{2}$ & No rot $\mathbf{b}$ & $\begin{array}{l}\text { No } \mathrm{H} \text { bond } \\
\text { Acceptors }\end{array}$ & $\begin{array}{l}\text { No H bond } \\
\text { donors }\end{array}$ & BBB & & \\
\hline Rutin & 610.52 & 269.43 & 6 & 16 & 10 & No & 2.43 & -0.29 Soluble \\
\hline Captopril & 217.29 & 96.41 & 4 & 3 & 1 & No & 1.46 & -0.38 Soluble \\
\hline
\end{tabular}

BBB: Blood-brain barrier, TPSA: Topological polar surface area 


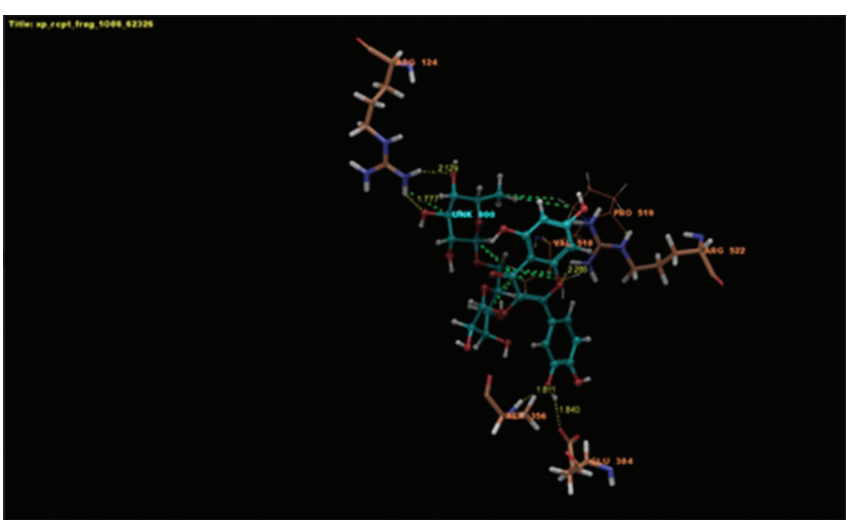

Fig. 1: Hydrogen-bonding interactions of rutin with Protein Data Bank ID: 1086 docking simulations in Glide 5.6

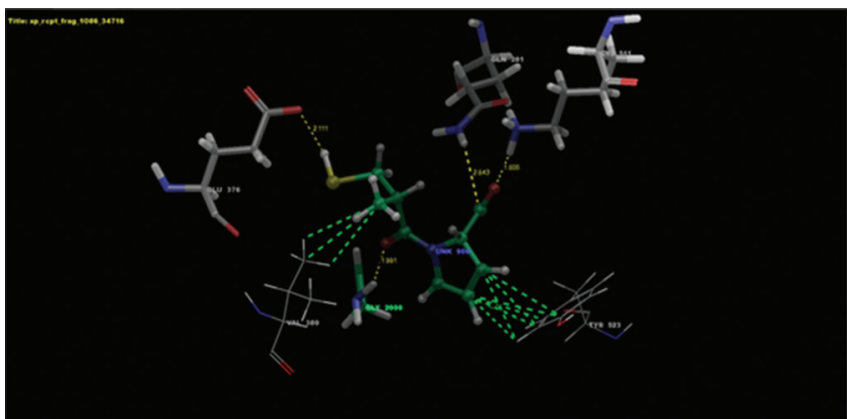

Fig. 2: Hydrogen-bonding interactions of rutin with Protein Data Bank ID: 1086 docking simulations in Glide 5.6

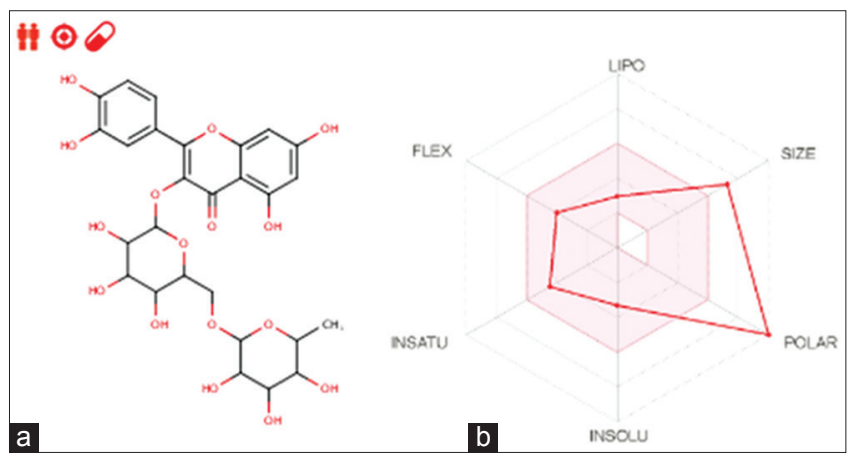

Fig. 3: Physiochemical properties of rutin. (a) Structure of rutin.

(b) Violations from Lipinski depicted in a red line

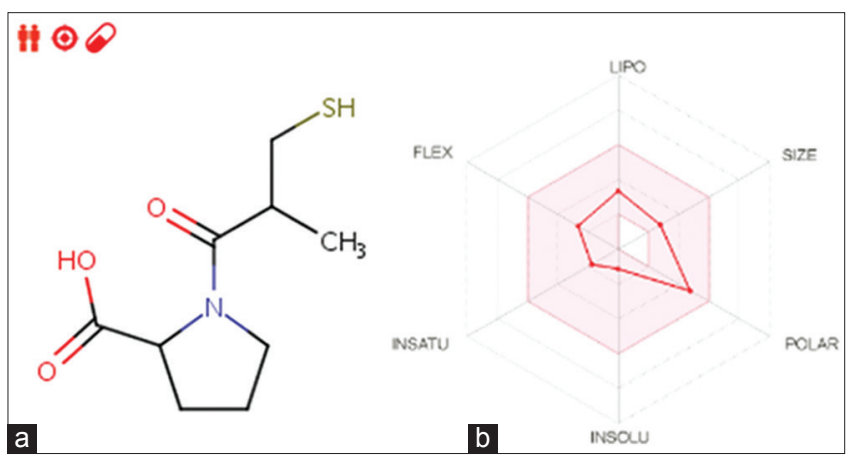

Fig. 4: Physiochemical properties of captopril. (a) Structure of captopril. (b) Zero violations from Lipinski depicted in redline

was monitored for its effect on body weight on L-NAME-induced hypertensive rats.
Docking studies of rutin

Rutin (total score: -9) demonstrated hydrogen-bonding interactions with Glu 384, Arg 124, and Ala 356. Docking results are depicted in Figs. 1 and 2.

Captopril (total score: -6.03) demonstrated hydrogen-bonding interactions with Glu 376, Gly 2000, Gln 281, and Lys 511.

\section{ADME properties}

Lipinski's rule of five is to evaluate drug-likeness or determine if a chemical compound with a certain pharmacological or biological activity has chemical properties and physical properties that would make it an orally active drug in humans. In the present study, rutin has three violations (such as molecular mass, hydrogen donor, and acceptors) of five. Captopril got zero violations which clearly indicated the probability for its higher oral bioavailability. Lipinski violations of rutin and zero violations of standard captopril were depicted in Figs. 3 and 4.

TPSA allows the prediction of transport properties of drug candidates in the intestines and BBB [19]. Rutin has TPSA of 269.43, and this high score of TPSA suggested that this molecule preferentially acts as hydrophilic in nature and cannot easily transport through the BBB when compared to captopril which has TPSA score of 96.41 clearly indicating lipophilic in nature.

The three violations of rule five for rutin indicated the probability for its less oral bioavailability [20]. In this study, there is no BBB score but found to have a high TPSA of 269.43, and this high score of TPSA suggested that this molecule was preferentially found to be hydrophilic in nature and cannot easily transport through the BBB. The ADME profile of rutin and captopril is given in Table 7.

\section{CONCLUSION}

From the above, it was concluded that the test compound rutin has antioxidant and antihypertensive activity. Docking studies of the rutin with target protein showed that this is a promising candidate which docks well with the target enzyme related to hypertension. Although rutin has less oral bioavailability in spite of being pharmacologically active, it might be transformed into sulfates or glucuronides to enhance its bioavailability. Thus, rutin can be considered for developing into a potent nutraceutical in the treatment of cardiovascular disorders, especially hypertension.

\section{ACKNOWLEDGMENTS}

The authors wish to thank management GRES, Laila Nutraceuticals, and principal, Gokaraju Rangaraju College of Pharmacy, Hyderabad, for providing technical support and laboratory facility for the study.

\section{AUTHORS' CONTRIBUTIONS}

Dr. M. Ganga Raju designed the study. Prem Prasad Goud carried out the experimental work; Dr. M. Ganga Raju and Dr. NVL Suvarchala Reddy drafted the manuscript, and they were involved in manuscript editing and finalization. All authors read and approved the final manuscript.

\section{CONFLICTS OF INTEREST}

All authors have no conflicts of interest to declare.

\section{REFERENCES}

1. Hertog MG, Hollman PC, Katan MB, Kromhout D. Intake of potentially anticarcinogenic flavonoids and their determinants in adults in the Netherlands. Nutr Cancer 1993;20:21-9.

2. Sampson L, Rimm E, Hollman PC, de Vries JH, Katan MB. Flavonol and flavone intakes in US health professionals. J Am Diet Assoc 2002; $102: 1414-20$ 
3. Benavente-García O, Castillo J. Update on uses and properties of citrus flavonoids: New findings in anticancer, cardiovascular, and antiinflammatory activity. J Agric Food Chem 2008;56:6185-205.

4. Romero JC, Reckelhoff JF. Role of angiotensin and oxidative stress in essential hypertension. Hypertension 1999;34:943-9.

5. Parslow RA, Sachdev P, Salonikas C, Lux O, Jorm AF, Naidoo D, et al. Associations between plasma antioxidants and hypertension in a community-based sample of 415 Australians aged 60-64. J Hum Hypertens 2005;19:219-26.

6. Berkban T, Boonprom P, Bunbupha S, Welbat JU, Kukongviriyapan U, Kukongviriyapan V, et al. Ellagic acid prevents L-NAME-induced hypertension via restoration of eNOS and p47phox expression in rats. Nutrients 2015;7:5265-80

7. Sjögren E, Thörn H, Tannergren C. In silico modeling of gastrointestinal drug absorption: Predictive performance of three physiologically based absorption models. Mol Pharm 2016;13:1763-78.

8. Ganga Raju M, Swetha K. Antidiabetic and hypolipidemic activity of methanolic extract of Sphaeranthus indicus in alloxan-induced diabetic rats. Indo Am J Pharm Res 2014;4:5218-25.

9. Reddy NVLS, Anarthe SJ, Subrahmanyam CV, Raghavendra NM. Antihypertensive, ACE inhibitory and antioxidant activity of whole plant of Rhynchosia beddomei. Asian J Pharmacol Toxicol 2015;3:13-8.

10. Nyadjeu P, Nguelefack-Mbuyo EP, Atsamo AD, Nguelefack TB, Dongmo AB, Kamanyi A, et al. Acute and chronic antihypertensive effects of Cinnamomum zeylanicum stem bark methanol extract in L-NAME-induced hypertensive rats. BMC Complement Altern Med 2013;13:27.

11. Akhila S, Aleykutty NA. Docking studies on identified constituents of Helicteres isora as antidiabetic agents. Int J Comput Appl 2012;45:8-13.
12. Malik A, Manan A, Mirza MU. Molecular docking and in silico ADMET studies of silibinin and glycyrrhetic acid anti-inflammatory activity. Trop J Pharm Res 2017;16:67-74.

13. Mon MM, Maw SS, Oo ZK. Quantitative determination of free radical scavenging activity and anti-tumor activity of some Myanmar herbal plants. Int J Med Health Biomed Bioeng Pharm Eng 2011;5:92-8.

14. McIntyre M, Bohr DF, Dominiczak AF. Endothelial function in hypertension: The role of superoxide anion. Hypertension 1999;34:539-45.

15. Li JS, Deng LY, Grove K, Deschepper CF, Schiffrin EL. Comparison of effect of endothelin antagonism and angiotensin-converting enzyme inhibition on blood pressure and vascular structure in spontaneously hypertensive rats treated with $\mathrm{N}$ omega-nitro-L-arginine methyl ester. Correlation with topography of vascular endothelin-1 gene expression. Hypertension 1996;28:188-95.

16. Ferrari AU, Daffonchio A, Albergati F, Mancia G. Inverse relationship between heart rate and blood pressure variabilities in rats. Hypertension 1987;10:533-7.

17. Virupaksha JH. Effect of Salix tetrasperma Roxbugh on fructoseinduced hypertension in rats. Int J Pharm Pharm Sci 2017;9:243-6.

18. Yamakawa T, Tanaka S, Tamura K, Isoda F, Ukawa K, Yamakura Y, et al. Wistar fatty rat is obese and spontaneously hypertensive. Hypertension 1995;25:146-50.

19. Dirar AI, Waddad AY, Mohamed MA, Mohamed MS, Osman WJ, Mohammed MS, et al. In silico pharmacokinetics and molecular docking of three leads isolated from Tarconanthus camphoratus. Int $\mathrm{J}$ Pharm Pharm Sci 2016;8:71-7.

20. Lipinski CA. Lead-and drug-like compounds: The rule-of-five revolution. Drug Discov Today Technol 2004;1:337-41. 